\title{
Syndrome de détresse respiratoire aiguë après intoxication au chloralose
}

\section{Acute Respiratory Distress Syndrome after Poisoning by Chloralose}

\author{
A. Derkaoui - S. Abdelkrim • M. Khatouf
}

Reçu le 13 février 2014 ; accepté le 16 avril 2014

(C) SFMU et Lavoisier SAS 2014

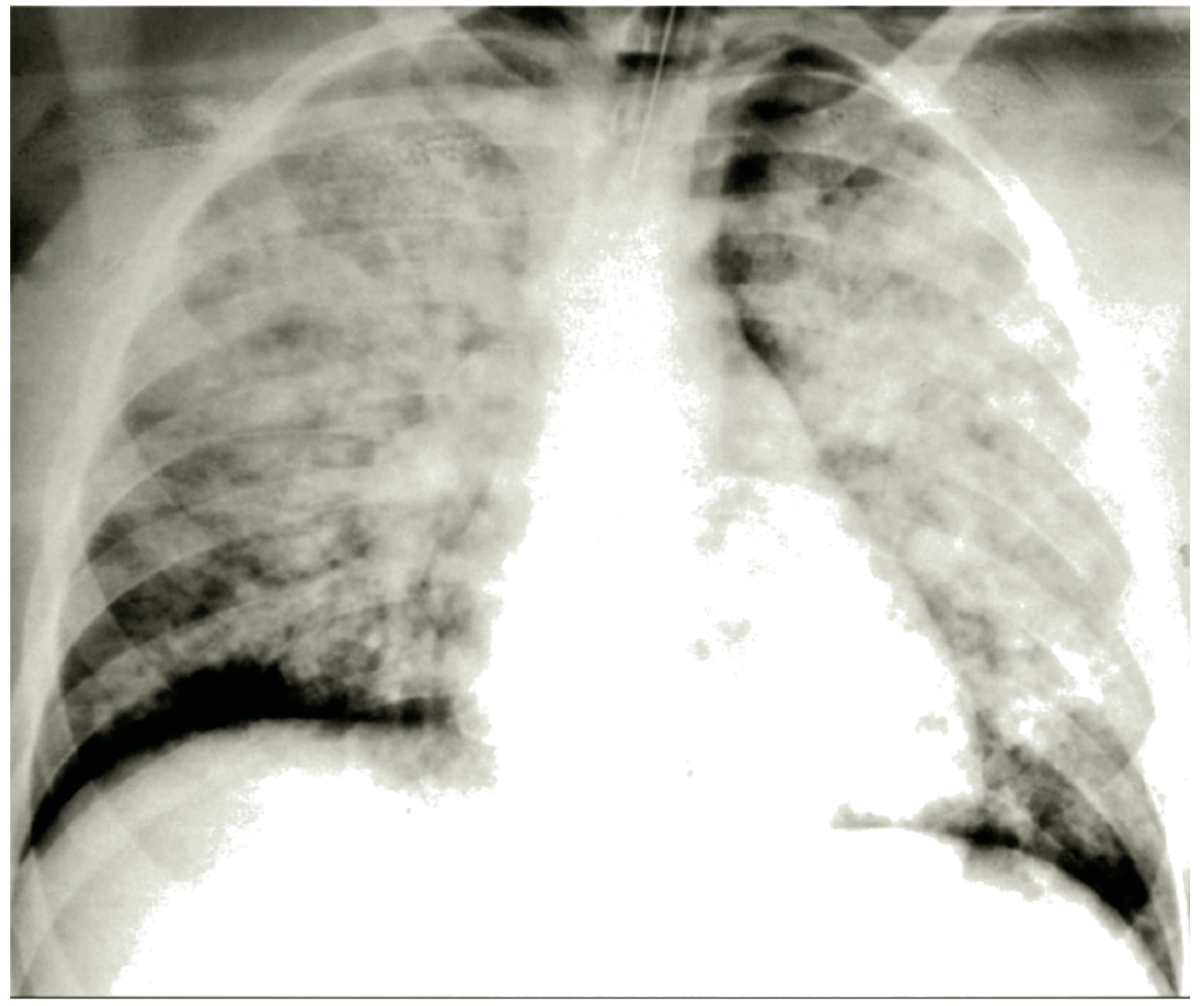

Fig. 1 Radiographie pulmonaire de face objectivant des opacités alvéolaires bilatérales confluentes

L'alphachloralose est un toxique fonctionnel fréquemment utilisé en agriculture comme rodenticide. L'intoxication par ce produit entraîne des troubles de la vigilance, une hyperexcitabilité musculaire, ainsi que des signes muscariniques entraînant un encombrement trachéobronchique avec hypoxémie. Nous rapportons le cas d'une patiente de 16 ans, admise

A. Derkaoui $(\bowtie) \cdot$ S. Abdelkrim $\cdot$ M. Khatouf Service de réanimation polyvalente A1, CHU Hassan II, 3000 Fès, Maroc

e-mail : alider1982@yahoo.fr
$6 \mathrm{~h}$ après ingestion volontaire d'une quantité imprécise d'alphachloralose. La symptomatologie clinique comportait des troubles de la conscience avec un score de Glasgow à 9 , des myoclonies et un syndrome de détresse respiratoire avec une hypoxémie majeure (rapport $\mathrm{PaO} 2 / \mathrm{FiO} 2=80 ; \mathrm{PaO} 2$ : pression partielle artérielle en oxygène, $\mathrm{FiO} 2$ : fraction inspirée en oxygène) et un syndrome alvéolo-interstitiel bilatéral (Fig. 1).

À noter que l'échocardiographie était normale à son admission. L'évolution était favorable après une prise en charge symptomatique ayant consisté en une intubation ventilation artificielle avec une sédation pendant $36 \mathrm{~h}$. 